\title{
A Guideline for Decision-making on Business Intelligence and Customer Relationship Management among Clinics
}

\author{
Nur Izzati Yusof ${ }^{1}$, Norziha Megat Mohd. Zainuddin ${ }^{2}$, \\ Noor Hafizah Hassan ${ }^{3}$, Nilam Nur Amir Sjarif ${ }^{4}$, \\ Suraya Yaacob ${ }^{5}$ \\ Advanced Informatics Department, Razak Faculty of \\ Technology and Informatics, Universiti Teknologi \\ Malaysia, 54100 Kuala Lumpur, Malaysia
}

\author{
Wan Azlan Wan Hassan ${ }^{6}$ \\ Computing Department, Faculty of Communication \\ Visual Art and Computing \\ Universiti Selangor, Bestari Jaya, 45600 \\ Selangor \\ Malaysia
}

\begin{abstract}
Business intelligence offers the capability to gain insights and perform better in decision-making by using a particular set of technologies and tools. A company's success to a certain extent depends on customers. The complementary of business intelligence and customer relationship management will improve the efficiency of organizations, hence increase productivity and revenue. Most research works on implementation of business intelligence and customer relationship management in organizations commonly concentrate on architecture, framework, and maturity model. The process on how to implement business intelligence and customer relationship management in an organization, especially in smaller domains has not yet been clarified which make some organizations unclear on how to implement business intelligence and customer relationship management. Thus, this study investigates the process involved in the implementation of business intelligence and customer relationship management among clinics. An infographic guideline was developed based on the six process of data mining which is known as Cross Industry Standard Process for Data Mining. Four elements of business intelligence decision-making process which were gather, store, access, and analyze were also included in the process of developing the guideline. Findings from an expert's review show that the increase of Content Validity Index was 0.7 , from 0.3 during the first iteration to $\mathbf{1 . 0}$ in the second iteration. Therefore, this result is acceptable. The guideline appears to be a useful instrument for practitioners to implement business intelligence and customer relationship management in their clinics, however the process involved in developing the guideline could be improvised from time to time.
\end{abstract}

Keywords-Business intelligence; customer relationship management; decision-making; guideline

\section{INTRODUCTION}

Business intelligence (BI) is seen as the technology and method for managing data in order to enhance decision-making [1]. BI technology provides businesses to gather, store, access and analyze huge volume of information in order to make better customer, supplier, employee, logistics, and infrastructure choices [2]. Decision maker in organizations will get benefits in making decision when implementing BI. Previous researchers have considered $\mathrm{BI}$ as a process and product [3]. The process consists of techniques used by organizations to create helpful data, or intelligence, which can assist organizations to survive and flourish. The product is data that will enable organizations to predict with a degree of certainty the behavior of their rivals, providers, clients, technologies, acquisitions, markets, goods and services, and the overall companies' climate. The advancement of BI system is significant in many industries, and this is no exception in healthcare.

In recent years, many studies on BI and CRM implementation in healthcare have been conducted and they only concentrated on larger domains that are generally exposed to the advancement of technology [4]. There are three commonly used models in implementing BI and CRM solution which are architecture, framework and maturity model. Thus, literatures on BI and CRM implementation in smaller organizations are required. The knowledge deficit on BI and CRM among practitioners in small organizations must be considered thoroughly. To address this issue, this study proposes a guideline for decision-making in implementing BI and CRM system among clinics. This guideline is useful to assist clinic practitioners in making better decision by fully utilizing the system.

Several attributes were considered in developing the guideline. Two employed instruments were questionnaire and guideline. Four elements of BI decision making process, six steps from cross-industry standard process for data mining (CRISP-DM) and two principles of infographics [5]-[7] were adapted in developing the guideline. Face validity and content validity were used to assess the questionnaire and the guideline. The result of evaluation was measured by using Context Validity Index (CVI). The purpose of this study is to address the issue on decision-making of practitioners in implementing BI and CRM system among clinics. More specifically, this study has two objectives:

1) To develop a guideline for decision-making in a clinic that can facilitate the clinician to fully utilize the implementation of BI and CRM.

2) To evaluate the developed guideline for decisionmaking in a clinic that can facilitate the clinician to fully utilize the implementation of BI and CRM. 
This article is organized into several sections. The immediate section that follows provides background information on business intelligence, customer relationship management, and infographics which clarify the domainspecific needs in the healthcare industry. Section III presents the methodology employed in the development of the guideline. Section IV presents the discussion on the findings. Finally, Section V presents the conclusion of this study by summarizing the contribution, limitation, and recommendation for future research.

\section{LITERATURE REVIEW}

The definitions made by researchers on business intelligence vary. According to Gartner Group (2012), BI can be defined as a comprehensive form of applications and technologies for gathering, storing, analyzing, sharing, and providing access to data to support companies to make better business decisions [8]. As mentioned by Gartner, BI helps decision makers to make better decision-making by transforming data into beneficial knowledge. Apart from that, $\mathrm{BI}$ also is defined as an environment where business users can easily and intuitively obtain consistent, reliable, perceptible and manipulated data to help managers search for organizational knowledge in the past, present and future [9]. From these definitions, it can be said that BI provides knowledge to decision makers in order to help them in making better decision regarding their business.

Customer relationship management (CRM) is an overall process of developing and maintaining lucrative customer relationships by providing superior customer value and satisfaction [10]. The word customer relationship management includes all the ideas that businesses use in relation to their customers, including the collection, storage and evaluation of client data, while considering the privacy and safety of the data [11]. Several researchers have suggested that CRM is applied to preserve the loyalty of customers as well as to increase profits. This is also applicable to healthcare organizations in which they can foster patient-clinic connection and provide more tangible advantages [12]-[14]. The researchers believe that the implementation of CRM system in healthcare is very important. This is because an efficient CRM system integrates individual health records, patient records and hospital information in order to provide a solution to manage healthrelated problems, advantages and expenses [15].

Studies on integration of BI and CRM systems have shown that this integration has created a path to customer loyalty [16]-[18]. Researchers have emphasized that the complementary use of CRM systems and business intelligence offers a holistic advantage that involves the enhancement of client profiling, simplifying client detection value, and evaluating the company's achievement in satisfying customers. BI can enhance incentives such as quicker transformation of potential into real customers, reduced amount of outgoing customers and increased sales among current customers. Therefore, in the modern business, CRM cannot be considered separately from business intelligence. These two develop a distinctive model that allows companies to predict customers' behaviors and make decisions based on these predictions and eventually, build long-term and profitable customer relationships [19]-[21].

The discussions on delivering information differ among studies conducted. Several studies have found that data visualization helps audiences to digest information better [22]. The use of infographics generates attention and interest as it utilizes words, numbers, icons, colors, and graphics that can be used in a more focused, organized, intuitive and engaging to tell a story behind the information and data [23]. Infographic is derived from the word information and graphic. It is used to disclose specific information to specific users. Infographic can be a tool for better understanding of knowledge, as it provides wider spectrum of information in visual form to audiences. It supports audiences to discover deeply and provides valuable facts that are hidden in complexity. Therefore, infographic can be described as a graphic design that combines data visualization, illustrations, text and image, together into a format that tells a complete story [24].

\section{Methodology}

This study applies a quantitative research methodology. A set of questionnaires was distributed to end users for the evaluation of the proposed guideline. The development of the guideline was based on the four elements of business intelligence decision-making concept. The elements were gather, store, access and analyze [2]. In addition, the process in developing the guideline was stimulated by the six processes of CRISP-DM [6]. Both the questionnaire and guideline were evaluated by experts to determine their usability.

\section{A. Respondents}

As suggested by Nielsen, three to five evaluators are enough to avoid more problems [25]. In this case study, five respondents, three experts and one end user were selected to participate in the validation and evaluation of the proposed guideline. The respondents and the experts were students and senior lecturers in a public university, while the end user was an owner of two dental clinics. The experts were chosen based on their expertise which was applicable to this case study. The list of experts and their expertise can be seen in Table I. The dental clinic was chosen because this clinic did not use any integration system with its other branch. This would cause difficulties in monitoring patients in clinical management. To add to that, the owner of this clinic was unaware of BI and CRM system. Therefore, the proposed guideline is hoped to assist decision makers in gathering more awareness and insights into the significance of having BI and CRM in order to improve the clinics' services.

TABLE. I. THE SPECIALIZATION AND DEPARTMENTS OF EXPERTS

\begin{tabular}{|l|l|l|l|}
\hline No. & Experts & Specialization & Department \\
\hline 1. & Expert 1 & Business Intelligence & Advanced Informatics \\
\hline 2. & Expert 2 & $\begin{array}{l}\text { Visualization and Interactive } \\
\text { Design }\end{array}$ & Advanced Informatics \\
\hline 3. & Expert 3 & $\begin{array}{l}\text { Information Systems, } \\
\text { Human-Computer Interaction } \\
\text { (HCI) }\end{array}$ & Advanced Informatics \\
\hline
\end{tabular}




\section{B. Research Instruments}

This study employed two instruments which were guideline and questionnaire. Fig. 1 shows the development of the instrument employed.

Fig. 1 shows that there are two types of instrument used in this study; they were a guideline and a questionnaire. The guideline had undergone one phase of validation which was on content validity. Meanwhile, the questionnaire had undergone two phases of validation which were face validity and content validity. Three different participants were involved in the validation and evaluation process. Five respondents were selected to participate in the face validity phase in which they were asked to validate whether the questionnaire could be understood or otherwise. Three experts were selected to participate in the content validity assessment of both the questionnaire and guideline. The changes in the content on questionnaire and the guideline were made according to their evaluation and validation. The last participant who was involved in the validation and evaluation measurement was an end user. The end user validated the usability and the likeliness of the guideline based on the given questionnaire. The Likert scale from strongly disagree to strongly agree was used to measure the acceptance of the guideline.

To develop an infographic design of the guideline, the data presentation and visualization tool was used. In this study, Visme, a free online tool that can create various types of infographic was used to design the guideline. The development of the guideline involved three components that must be considered as illustrated in Fig. 2.

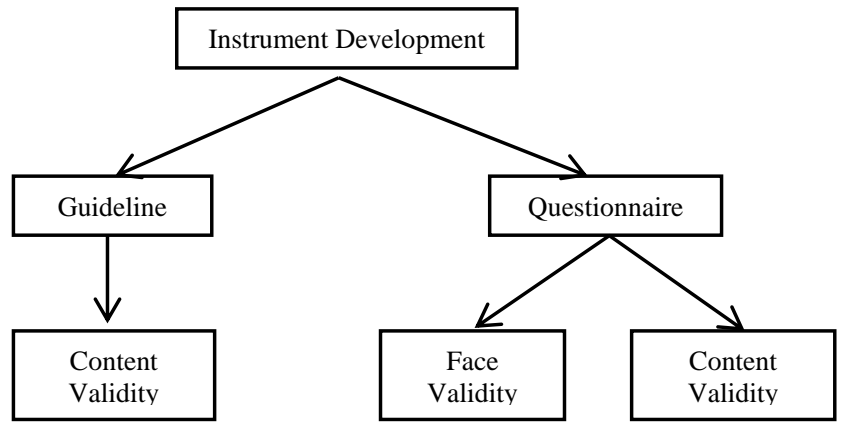

Fig. 1. Instrument for Decision-Making Guideline.

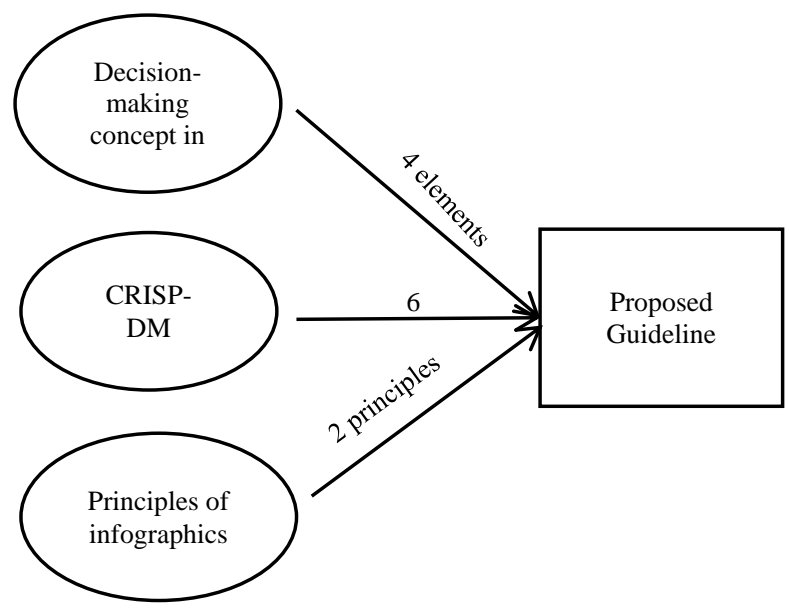

Fig. 2. Guideline Development.
According to Fig. 2, the proposed guideline was developed based on four elements of decision-making concept in BI, six processes of CRISP-DM and the principles of infographics [2], [6], [7]. Four elements of decision-making process in BI included (i) gather, (ii) store, (iii) access, and (iv) analyze. The six processes of CRISP-DM were business understanding, data understanding, data preparation, modelling, evaluation, and deployment. Meanwhile, the two principles of infographics [7] are:

1) Process infographic: This type of infographic shows the step by step process by visualizing the number and flow of the process in a connected line so that audience can quickly understand a process.

2) Informational infographic: This type of infographic shows information to audience. This infographic provides extra information to audiences by adding a descriptive header so that audience can understand the infographic better.

The proposed guideline consisted of six processes as can be seen in Table II. The processes were grouped into four elements of decision-making process in BI. The elements were used in the questionnaire to differentiate the processes of decision-making that were relevant to those elements so that the respondents would able to comprehend BI and CRM implementation better. Table III shows the items in the questionnaire.

The proposed guideline contains of six processes adopted from CRISP-DM [6]. They are:

1) Understand your business: A clear objective and the obstacles found in the clinic must be clearly identified.

2) Understand your data: Collect data of patients and drugs inventories as well as other clinic management matters.

3) Prepare your data: The data of the patients, drugs inventories, clinic tools and other related management matters must be recorded accurately. Irrelevant, old and redundant data has to be removed and cleaned.

4) Adopt online database system: Store and update the data in an online database so that the data is integrated and can be easily accessed anywhere and anytime.

5) Assess the data: Access the data to identify any problem occurred and overcome the problem as soon as possible.

6) Monitor, maintain and iterate usage: Regular assessment on current business performance to improve decision-making.

TABLE. II. SIX PROCESSES OF THE GUIDELINE

\begin{tabular}{|c|c|c|}
\hline $\begin{array}{l}\text { Number of } \\
\text { Process }\end{array}$ & Description & Element of BI \\
\hline 1. & Understand your business problem & \multirow{2}{*}{ Gather } \\
\hline 2. & Understand your data & \\
\hline 3. & Prepare your data & \multirow{2}{*}{ Store } \\
\hline 4. & Adopt online database system & \\
\hline 5. & Assess the data & Access \\
\hline 6. & Monitor, maintain and iterate usage & Analyze \\
\hline
\end{tabular}


TABLE. III. THE ITEMS OF QUESTIONNAIRE

\begin{tabular}{|c|c|c|}
\hline Item & Items & Reference \\
\hline \multicolumn{3}{|c|}{ Gather } \\
\hline GI & $\begin{array}{l}\text { The terms used in these steps is easy to } \\
\text { understand and can be followed. }\end{array}$ & [26] \\
\hline $\mathrm{G} 2$ & $\begin{array}{l}\text { I must identify the objective of my clinic } \\
\text { clearly. }\end{array}$ & [27] \\
\hline G3 & $\begin{array}{l}\text { I must identify any limitation occurred before I } \\
\text { proceed to my future project plan. }\end{array}$ & [27] \\
\hline G4 & $\begin{array}{l}\text { The medical data (including patients record, } \\
\text { drugs inventories, etc.) must be well-recorded. }\end{array}$ & Self-developed \\
\hline G5 & $\begin{array}{l}\text { Patients satisfaction towards the clinic services } \\
\text { is my priority. }\end{array}$ & Self-developed \\
\hline \multicolumn{3}{|l|}{ Store } \\
\hline $\mathrm{S} 1$ & $\begin{array}{l}\text { The terms used in these steps is easy to } \\
\text { understand and can be followed. }\end{array}$ & [26] \\
\hline $\mathrm{S} 2$ & $\begin{array}{l}\text { Medical data (including patients record, drugs } \\
\text { inventories, etc.) should be recorded } \\
\text { accordingly to its category. }\end{array}$ & {$[27]$} \\
\hline S3 & $\begin{array}{l}\text { All redundant or same data have to be removed } \\
\text { as well as old and irrelevant data. }\end{array}$ & [27] \\
\hline S4 & $\begin{array}{l}\text { If I store the medical data in an online database } \\
\text { system, it will help me to access and analyze } \\
\text { the medical record anywhere and anytime. }\end{array}$ & {$[27]$} \\
\hline \multicolumn{3}{|c|}{ Access } \\
\hline Ac1 & $\begin{array}{l}\text { The terms used in this step is easy to understand } \\
\text { and can be followed. }\end{array}$ & [26] \\
\hline Ac2 & $\begin{array}{l}\text { The record of patients' data has to be evaluated } \\
\text { to encounter any issues involved (i.e.: illness, } \\
\text { allergic, bill, total patients visit). }\end{array}$ & Self-developed \\
\hline Ac3 & $\begin{array}{l}\text { The record of drugs inventories has to be } \\
\text { assessed to aware any low and waste stocks. }\end{array}$ & Self-developed \\
\hline Ac4 & $\begin{array}{l}\text { Cash flow of the clinic is important to measure } \\
\text { the financial availability. }\end{array}$ & {$[27]$} \\
\hline Ac5 & $\begin{array}{l}\text { It is important to assess patients' feedbacks and } \\
\text { satisfaction. }\end{array}$ & Self-developed \\
\hline \multicolumn{3}{|c|}{ Analyze } \\
\hline An1 & $\begin{array}{l}\text { The terms used in this step is easy to understand } \\
\text { and can be followed. }\end{array}$ & [26] \\
\hline An2 & $\begin{array}{l}\text { It is important to measure clinic performance } \\
\text { regularly. }\end{array}$ & {$[27]$} \\
\hline An3 & $\begin{array}{l}\text { Current business report is important in } \\
\text { decision-making to ensure better management } \\
\text { performance in future. }\end{array}$ & {$[27]$} \\
\hline An 4 & $\begin{array}{l}\text { Patients' experience and satisfaction is one of } \\
\text { the most keys to success. }\end{array}$ & {$[28]$} \\
\hline An5 & $\begin{array}{l}\text { An adequate service will bond a good } \\
\text { relationship with patients to preserve their } \\
\text { loyalty. }\end{array}$ & Self-developed \\
\hline \multicolumn{3}{|c|}{ Overall Evaluation } \\
\hline E1 & $\begin{array}{l}\text { The title and the content of the guideline is } \\
\text { understandable. }\end{array}$ & {$[26]$} \\
\hline $\mathrm{E} 2$ & $\begin{array}{l}\text { The guideline presents a complete, clear, well- } \\
\text { formed message and is logically structured. }\end{array}$ & [26] \\
\hline E3 & $\begin{array}{l}\text { The graphic of the guideline includes relevant } \\
\text { text, images and consistent design elements. }\end{array}$ & Self-developed \\
\hline $\mathrm{E} 4$ & $\begin{array}{l}\text { The guideline enables me to improve my } \\
\text { knowledge on decision-making of customer } \\
\text { relationship management. }\end{array}$ & Self-developed \\
\hline
\end{tabular}

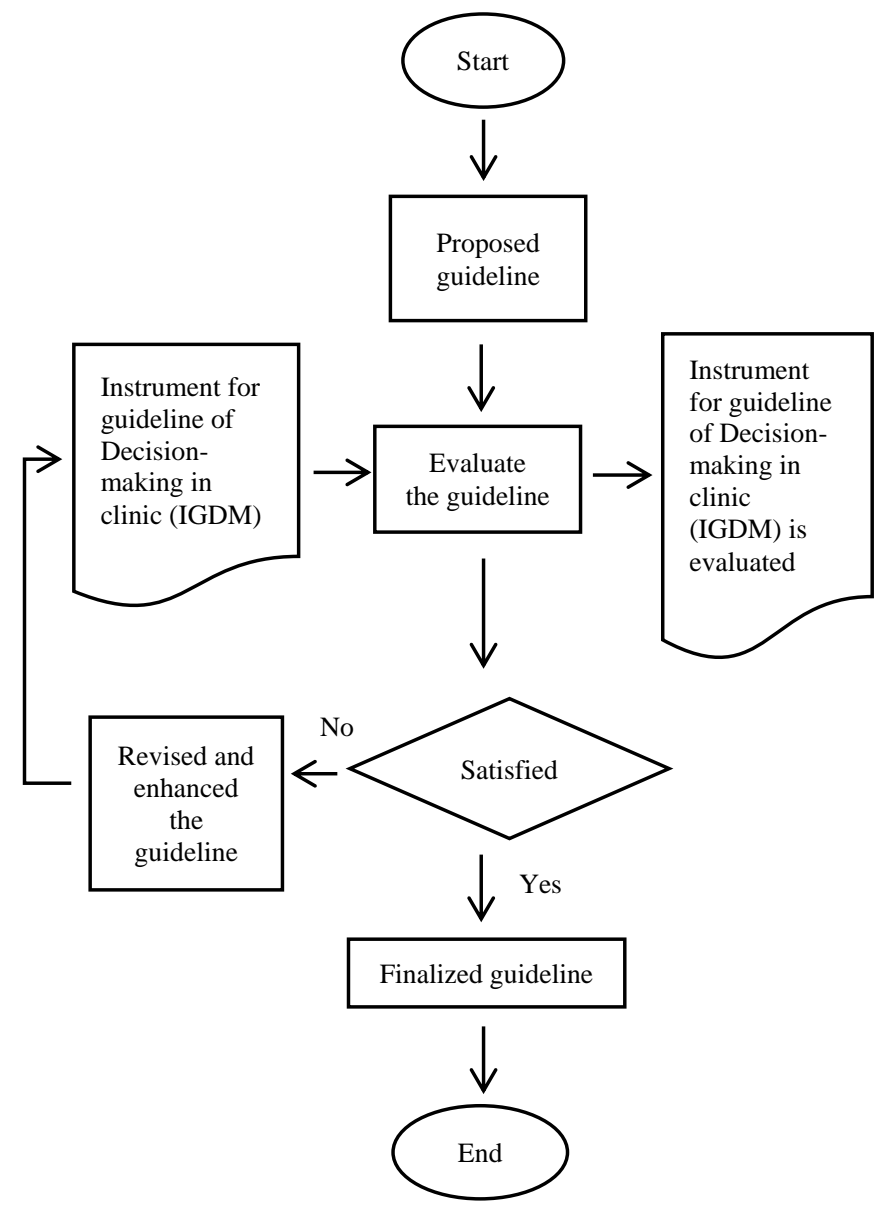

Fig. 3. Flowchart of Guideline Evaluation.

\section{Research Procedures}

Before the guideline can be employed, evaluation processes must be conducted first. Fig. 3 shows the flowchart of the evaluation of the guideline.

The process started with proposing a guideline. The guideline was evaluated by employing face validity and content validity tests. Face validity was used to identify whether the term and sentences used could be easily understood. The content validity was used to validate the content of the guideline in terms of graphics and information that was included in the guideline. Once the guideline was approved, it can be used. Otherwise, the guideline had to be revised and improvised. The revised guideline will then repeat the evaluation process until it would approve and appropriate to be used.

\section{FINDINGS}

The experts were asked to validate the content of the questionnaire and the infographic guideline. In doing this, the instrument was sent to experts to be validated and they were modified based on the comments made by the experts. Three experts were selected for the content validity. The first expert had visualization expertise, the second expert had business intelligence expertise, and the third expert had questionnaire expertise. Table IV provides the summary on the comments made by the experts. 
TABLE. IV. EXPERTS' COMMENTS ON CONTENT VALIDITY

\begin{tabular}{|c|c|c|}
\hline No. & Experts & Comments \\
\hline 1. & Expert 1 & $\begin{array}{l}\text { a. The question is too general. Try to precise and } \\
\text { deep further the element of infographic in line } \\
\text { with the element of questionnaire. } \\
\text { b. The flow of the information is according to the } \\
\text { process need to be taken - clarity of the process } \\
\text { through information flow. } \\
\text { c. Include cue in the infographic by using } \\
\text { metaphor/analogy/gestalt. } \\
\text { d. Emphasized right keyword. Increase font size. } \\
\text { Reduce irrelevant picture. }\end{array}$ \\
\hline 2. & Expert 2 & $\begin{array}{l}\text { a. The question is more on infographic. Add more } \\
\text { element of BI in the questionnaires. } \\
\text { b. Restructure the flow of the guideline. Try to } \\
\text { follow the process of CRISP-DM. } \\
\text { c. Some content of the guideline is not clear. } \\
\text { d. Relate the questions to BI decision- } \\
\text { making/decision-making in clinic. }\end{array}$ \\
\hline 3. & Expert 3 & $\begin{array}{l}\text { a. Some wording needs to be revised so that the } \\
\text { meaning can reflect the situation better. } \\
\text { b. Add extra explanation on BI terms to give } \\
\text { understanding for audience who does not have } \\
\text { information technology (IT) background. }\end{array}$ \\
\hline
\end{tabular}

TABLE. V. CONTENT VALIDITY INDEX (CVI) - BEFORE REVISED

\begin{tabular}{|l|l|l|l|l|l|}
\hline $\begin{array}{l}\text { Questions/ } \\
\text { Items }\end{array}$ & $\begin{array}{l}\text { Expert } \\
\mathbf{1}\end{array}$ & $\begin{array}{l}\text { Expert } \\
\mathbf{2}\end{array}$ & $\begin{array}{l}\text { Expert } \\
\mathbf{3}\end{array}$ & $\begin{array}{l}\text { No. of } \\
\text { Agreement }\end{array}$ & I/CVI \\
\hline Q1 & 2 & 1 & 2 & 0 & 0 \\
\hline Q2 & 2 & 4 & 2 & 1 & 0.333333 \\
\hline Q3 & 4 & 2 & 4 & 2 & 0.666667 \\
\hline Q4 & 2 & 4 & 4 & 2 & 0.666667 \\
\hline Q5 & 2 & 4 & 4 & 2 & 0.666667 \\
\hline Q6 & 4 & 1 & 2 & 1 & 0.333333 \\
\hline Q7 & 2 & 1 & 2 & 0 & 0 \\
\hline Q8 & 2 & 1 & 2 & 0 & 0 \\
\hline Q9 & 2 & 1 & 2 & 0 & 0 \\
\hline Q10 & 2 & 4 & 4 & 2 & 0.666667 \\
\hline Q11 & 2 & 4 & 2 & 1 & 0.333333 \\
\hline Q12 & 2 & 2 & 2 & 0 & 0 \\
\hline Q13 & 2 & 2 & 4 & 1 & 0.333333 \\
\hline Q14 & 2 & 2 & 2 & 0 & 0 \\
\hline Q15 & 2 & 1 & 2 & 0 & 0 \\
\hline Q16 & 2 & 2 & 2 & 0 & 0 \\
\hline Q17 & 2 & 2 & 2 & 0 & 0 \\
\hline Q18 & 2 & 2 & 4 & 1 & 0.333333 \\
\hline Q19 & 4 & 2 & 4 & 2 & 0.666667 \\
\hline Q20 & 4 & 2 & 2 & 1 & 0.333333 \\
\hline Q21 & 4 & 2 & 2 & 1 & 0.333333 \\
\hline Q22 & 4 & 2 & 4 & 2 & 0.666667 \\
\hline Q23 & 4 & 2 & 4 & 2 & 0.666667 \\
\hline & & & & S/CVI & 0.304348 \\
\hline
\end{tabular}

In order to evaluate the expert result on content validity of the questionnaire, the Content Validity Index (CVI) was used in this study. Content validity is the degree to which an instrument has an appropriate sample of items for the construct being measured and is an important procedure in scale development. CVI is the most widely used index in quantitative evaluation [29]. A CVI value can be computed for each question on a scale which refers to I-CVI, and the overall scale which refers to S-CVI. In this study, the experts were asked to rate the relevance of each item, on a 4-point scale. The scale used in this study was $1=$ Not Relevant, 2=Somewhat Relevant, 3=Relevant, 4=Highly Relevant. Researchers recommend that a scale with excellent content validity should be composed of I-CVIs of 0.78 or higher and S-CVI/UA and SCVI/Ave of 0.8 and 0.9 or higher, respectively. The results of the CVI on pre and post revision are depicted in Table $\mathrm{V}$ and Table VI.

Table V and Table VI show the results of Content Validity Index. Before the questionnaire was revised, the computed result of S/CVI was 0.304348 . This result expressed that the questionnaire needed a lot of improvement. After the questionnaire was revised, the computed result of S/CVI was 1. This proved that the revised questionnaire was accepted to be used.

TABLE. VI. CONTENT VALIDITy INDEX (CVI) - AFTER REVISED

\begin{tabular}{|c|c|c|c|c|c|}
\hline $\begin{array}{l}\text { Questions/ } \\
\text { Items }\end{array}$ & $\begin{array}{l}\text { Expert } \\
1\end{array}$ & $\begin{array}{l}\text { Expert } \\
2\end{array}$ & $\begin{array}{l}\text { Expert } \\
3\end{array}$ & $\begin{array}{l}\text { No. of } \\
\text { Agreement }\end{array}$ & I/CVI \\
\hline Q1 & 4 & 4 & 4 & 3 & 1 \\
\hline Q2 & 3 & 4 & 4 & 3 & 1 \\
\hline Q3 & 4 & 3 & 3 & 3 & 1 \\
\hline Q4 & 3 & 4 & 4 & 3 & 1 \\
\hline Q5 & 4 & 4 & 4 & 3 & 1 \\
\hline Q6 & 4 & 4 & 3 & 3 & 1 \\
\hline Q7 & 4 & 3 & 4 & 3 & 1 \\
\hline Q8 & 4 & 4 & 4 & 3 & 1 \\
\hline Q9 & 3 & 4 & 4 & 3 & 1 \\
\hline Q10 & 4 & 4 & 3 & 3 & 1 \\
\hline Q11 & 4 & 4 & 4 & 3 & 1 \\
\hline Q12 & 3 & 3 & 4 & 3 & 1 \\
\hline Q13 & 4 & 4 & 4 & 3 & 1 \\
\hline Q14 & 4 & 4 & 3 & 3 & 1 \\
\hline Q15 & 3 & 4 & 4 & 3 & 1 \\
\hline Q16 & 4 & 4 & 4 & 3 & 1 \\
\hline Q17 & 4 & 4 & 3 & 3 & 1 \\
\hline Q18 & 4 & 3 & 4 & 3 & 1 \\
\hline Q19 & 4 & 4 & 4 & 3 & 1 \\
\hline Q20 & 3 & 4 & 4 & 3 & 1 \\
\hline Q21 & 4 & 3 & 4 & 3 & 1 \\
\hline Q22 & 4 & 4 & 3 & 3 & 1 \\
\hline \multirow[t]{2}{*}{ Q23 } & 3 & 4 & 4 & 3 & 1 \\
\hline & & & & S/CVI & 1 \\
\hline
\end{tabular}


Based on the experts' review, the infographic guideline needed to be revised so that the audience could gain better understanding. The title, picture, the steps, and the font were the elements that needed to be revised. The results of the guideline pre and post revision are depicted in Fig. 4 and Fig. 5.
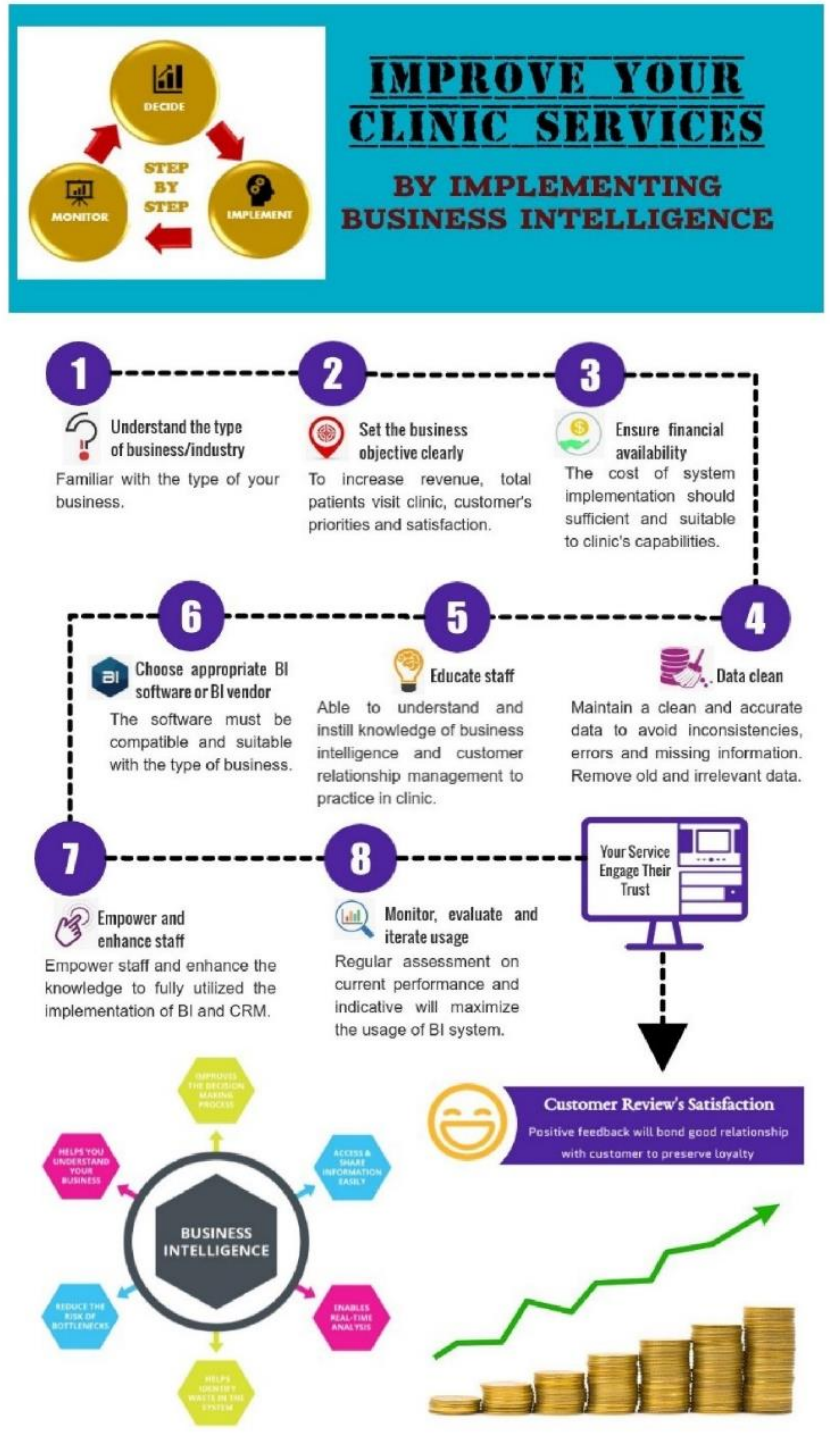

Fig. 4. Infographic Guideline I-before Revised.
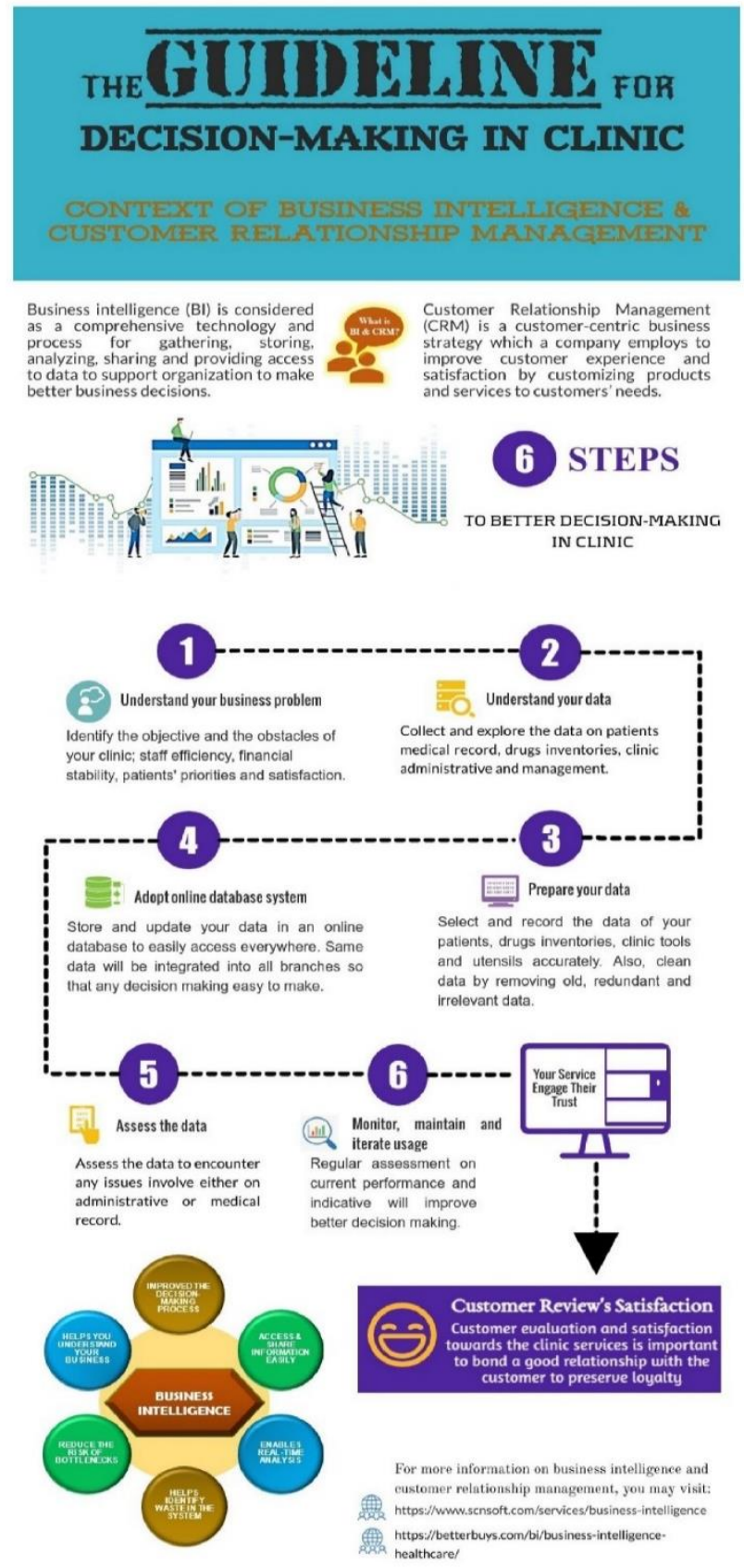

Fig. 5. Infographic Guideline II-after Revised. 
Based on Fig. 5, it can be observed that the title, the steps, and the picture were the elements that were revised. From the guideline (before revised) the title from "Improve Your Clinic Service by Implementing Business Intelligence" was been changed to "The Guideline for Decision-Making in Clinic, Context of Business Intelligence and Customer Relationship Management" (after revised). The irrelevant picture was also removed. For example, the picture of the coins did not fit the research. Infographic Guideline II had included more information on the definition of BI and CRM, and also the given link for audience to know more about BI and CRM. The expert asked to put the link for easy access among the audience to know more about BI and CRM. Apart from that, the most important criteria of the guideline were the steps involved in decision-making. From the experts' review, instead of providing steps to implement $\mathrm{BI}$; which was too general, the expert recommended to change the steps on decision-making according to the CRISP-DM process. Therefore, this study has followed the steps involved in CRISP-DM and has been slightly revised to fit the context of the research. Based on Infographic Guideline I, there were 8 steps involved to implement the BI and CRM. Meanwhile, after the revision, only 6 steps were used in Infographic Guideline II in line with the steps included in CRISP-DM. The summary of the changes before and after the guideline was revised and it can be seen in Table VII.

TABLE. VII. SUMMARY OF INFOGRAPHIC GUIDELINE'S CHANGES ITEM

\begin{tabular}{|l|l|l|l|}
\hline No. & Item & Before Changes & After Changes \\
\hline 1. & Title & $\begin{array}{l}\text { Improve Your Clinic } \\
\text { Service by Implementing } \\
\text { Business Intelligence. }\end{array}$ & $\begin{array}{l}\text { The Guideline for Decision- } \\
\text { Making In Clinic, Context of } \\
\text { Business Intelligence and } \\
\text { Customer Relationship } \\
\text { Management. }\end{array}$ \\
\hline 2. & Steps & 8 steps. & 6 steps. \\
\hline 3. & Info & $\begin{array}{l}\text { Lack of BI and CRM } \\
\text { information. }\end{array}$ & $\begin{array}{l}\text { Include the information of BI } \\
\text { and CRM. }\end{array}$ \\
\hline 4. & Picture & $\begin{array}{l}\text { Irrelevant picture that does } \\
\text { not related to the element } \\
\text { of BI and CRM. }\end{array}$ & $\begin{array}{l}\text { The irrelevant picture has } \\
\text { been removed. }\end{array}$ \\
\hline
\end{tabular}

\section{DisCUSSION AND CONCLUSIONS}

This study identified three attributes of developing guideline for decision-making to implement BI and CRM among clinics. The attributes contained four elements of decision-making concept in BI, six process adapted from CRISP-DM process and two principles of infographics. This guideline is useful in assisting practitioners to make decisions by implementing BI and CRM. Face validity and content validity were used to evaluate the guideline. CVI shows the result of 1 after experts' reviews. The infographic guideline was also improvised. The decision-making to implement BI and CRM is important nowadays as previous studies have also emphasized the importance of implementing BI and CRM which would improve the performance of business [13], [14], [30]-[32].

The implementation of BI and CRM is expanding each day. Many large companies have implemented the BI and CRM with the proper standard. Yet, small companies are still way behind in implementing BI and CRM and lack expertise to fully utilize it. In this project, a clinic has been selected as a case study. Since the population is increasing, the need of improving health care management is important to help people with different types of illness to be treated well. Since technology is advancing, the efficiency of operation and management of clinics need to be aligned with the latest technology. However, without a proper guideline to help decision makers to decide carefully for the sake of the performance of their clinics, the use of high technology will give a little impact to them. Therefore, a guideline for decisionmaking on CRM among clinics is proposed to assist decision makers in making better decisions. It is an advantage for them to know better the use of BI and CRM.

Time consumption contributes one of the main limitations of this study. The challenge was to find a clinic that wanted to participate since many clinics were too occupied with their daily operations and handling patients, not many were ready to participate due to their tight schedules. Apart from that, another limitation was finding the clinics that fit into the perimeter of this study. Much time was spent on making phone calls and paying visits that these premises to find the ones that were suitable for this study.

The proposed guideline is recommended to be used in various type of industries, instead of just focusing only on health care institutions. The purpose is to improve the reliability of the results and allowing the research to represent various industries. It is also hoped that this study will further add to the pool of knowledge on BI and CRM and opens more doors for similar research works to be conducted in the future.

REFERENCES

[1] P. Wanda and S. Stian, "The Secret of my Success: An exploratory study of Business Intelligence management in the Norwegian Industry," Procedia - Procedia Comput. Sci., vol. 64, no. 1877, pp. 240-247, 2015.

[2] C. Lennerholt, J. van Laere, and E. Söderström, "Implementation Challenges of Self Service Business Intelligence: A Literature Review," Proc. 51st Hawaii Int. Conf. Syst. Sci., vol. 9, pp. 5055-5063, 2018.

[3] N. Caseiro and A. Coelho, "The influence of Business Intelligence capacity, network learning and innovativeness on startups performance," no. $2017,2018$.

[4] L. Gastaldi, A. Pietrosi, S. Lessanibahri, M. Paparella, A. Scaccianoce, G. Provenzale, M. Corso, and B. Gridelli, "Technological Forecasting \& Social Change Measuring the maturity of business intelligence in healthcare : Supporting the development of a roadmap toward precision medicine within ISMETT hospital," Technol. Forecast. Soc. Chang., vol. 128, no. August 2017, pp. 84-103, 2018.

[5] A. Ahmed, "Exploration of business intelligence using Oralce B.I (OBIEE)," 2017. [Online]. Available: https://www.slideshare.net/ AneelAhmed/exploration-of-business-intelligence-using-oralce-bi-obiee.

[6] H. Kemper, H. Baars, and H. Lasi, "Business Intelligence and Performance Management,” Bus. Intell. Perform. Manag., pp. 13-27, 2013.

[7] S. Mcguire, "9 Types of Infographics and When to Use Them [+ Infographic Templates]," 2019. [Online]. Available: https://venngage.com/blog/9-types-of-infographic-template/. [Accessed: 15-Jun-2019].

[8] O. Ali, P. Crvenkovski, and H. Johnson, "Using a Business Intelligence Data Analytics Solution in Healthcare A case study: Improving Hip Fracture Care Processes in a Regional Rehabilitation System," 2016.

[9] S. Williams and N. Williams, The Profit Impact of Business Intelligence. 2010.

[10] A. Sen and A. P. Sinha, "IT alignment strategies for customer relationship management," Decis. Support Syst., vol. 51, no. 3, pp. 609619, 2011. 
[11] C. Mati and L. Ilie, "Customer relationship management in the insurance industry," vol. 15, no. 14, pp. 1138-1145, 2014.

[12] P. L. H. C.L. Hsu, C. Chiu, "“A Constraint-Based Optimization Mechanism for Patient Satisfaction,' Knowledge-Based Intelligent Information and Engineering Systems." 2014.

[13] Y. M. Baashar, "An Integrative Perspective for CRMS Implementation in Healthcare in Malaysia," no. 100, 2014.

[14] M. N. Almunawar and M. Anshari, "Improving Customer Service in Healthcare," no. August 2018, 2011.

[15] M. Boris, "Application Of Customer Relationship Management Strategy ( Crm ) In Different Business Areas Boris Milovic," vol. 9, pp. 341-354, 2012.

[16] A. Habul, "Business Intelligence and Customer Relationship Management," pp. 169-174, 2010.

[17] S. R. Shinde and Sunjita, "Integration between Customer Relationship Management and Business Intelligence," 2018.

[18] A. Khan, N. Ehsan, E. Mirza, and S. Zahoor, "Integration between Customer Relationship Management ( CRM ) and Data Warehousing," vol. 1, pp. 239-249, 2012.

[19] Y. Gupta and N. Sharma, "When BI Meets CRM: An Emerging Concept in Retail Industry," nternational J. Bus. Anal. Intell. New Delhi, vol. 1, no. 1, pp. 41-48, 2013.

[20] A. Habul, A. Pilav-Velić, and K. Emir, "Customer Relationship Management and Business Intelligence," Intech, vol. i, no. tourism, p. 13, 2016.

[21] R. Gujrati, "CRM for retailers: Business intelligence in retail CRM," vol. 2, no. 1, pp. 24-29, 2016.

[22] M. Lonsdale and D. Lonsdale, Information Visualization Guidelines. 2019.
[23] K. T. Lyra, S. Isotani, R. C. D. Reis, L. B. Marques, L. Z. Pedro, P. A. Jaques, and I. I. Bitencourt, "Infographics or Graphics+Text: Which material is best for robust learning?," Proc. - IEEE 16th Int. Conf. Adv. Learn. Technol. ICALT 2016, pp. 366-370, 2016.

[24] N. S. Arum, "Infographic: Not Just a Beautiful Visualisation," Univ. Birmingham, 2017.

[25] C. W. Turner, J. R. Lewis, and J. Nielsen, "Determining Usability Test Sample Size," vol. 3, no. 2, pp. 3084-3088, 2006.

[26] J. C. Dunlap and P. R. Lowenthal, "Getting graphic about infographics: design lessons learned from popular infographics," vol. 6529, no. September, 2016.

[27] G. R. Gangadharan and S. N. Swami, "Business Intelligence Systems: Design and Implementation Strategies," 26th Int. Conf. Inf. Technol. Interfaces ITI, pp. 139-144, 2004.

[28] H. Han and S. S. Hyun, "Customer retention in the medical tourism industry: Impact of quality, satisfaction, trust, and price reasonableness," Tour. Manag., vol. 46, pp. 20-29, 2015.

[29] Z. N. D. X. X. Bao and Y. X. Ban, "Content validity index in scale development," 2012.

[30] Y. Li, J. Huang, and T. Song, "Information \& Management Examining business value of customer relationship management systems: IT usage and two-stage model perspectives," Inf. Manag., no. July, pp. 1-11, 2018.

[31] H. Moghimi, E. Healthcare, S. Vaughan, E. Healthcare, S. Mcconche, and E. Healthcare, "How Do Business Analytics and Business Intelligence Contribute to Improving Care Efficiency ?," pp. 3408-3415, 2016.

[32] D. Coelho, J. Miranda, F. Portela, J. Machado, and M. Filipe, "Towards of a Business Intelligence Platform to Portuguese Misericórdias," Procedia - Procedia Comput. Sci., vol. 100, pp. 762-767, 2016. 